\title{
Modelling and Manufacturing of Progressive die for Mechanical Press Operations
}

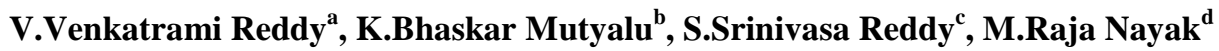 \\ a,d Assistant Professor, 2Sr.Assistant Professor, 3Associate Professor \\ a,c,d Lakireddy Bali Reddy College of Engineering, Mylavaram, India. \\ ${ }^{\mathrm{b} S}$ Sai Spurthi Institute of Technology, Sathupally, India. \\ âmail id: vvreddy.324@gmail.com
}

Article History: Received: 10 November 2020; Revised 12 January 2021 Accepted: 27 January 2021; Published online: 5 April 2021

\begin{abstract}
A progressive die is a type of die in which multiple operations performed in a single stroke, which was mostly used in sheet metal operations. The working process of sheet metal is widely used in all manufacturing industries such as mechanical, defense and automotive etc. The key advantage of metal working process involves enhancement of production rate and cost reduction. This paper is aimed to develop a multi-functional die which can perform simultaneously both punching and blanking operations in one stroke. The present work is mainly focused on modeling and manufacturing of the die components, where PRO-E was used for modelling and FANUC controlled CNC machine was used to execute and prepared part program.
\end{abstract}

Keywords: Mechanical press, Progressive Die, Pro-E, CNC Milling

\section{Introduction}

Generally progressive dies are used for fabrication of different sheet metal component grouped under mass production. Designing of a progressive die [1] is intricate process as it consumes $20 \%$ further time from the initial design step to the end stamping operation. The variety of components may generates using progressive die operation, therefore its design insists eminent knowledge level and expertise in design procedure, standards for making a qualified die [2-6]. Progressive dies coalesce a multiple types of dies, punches and occupied in a appropriate sequence in various work stations together comprises the complete die [7].During the operation strip goes through each work place where it sheared and formed, in the final stage the finished sheet metal part is cut off from the strip. The various elements of progressive die was showed in fig 1.

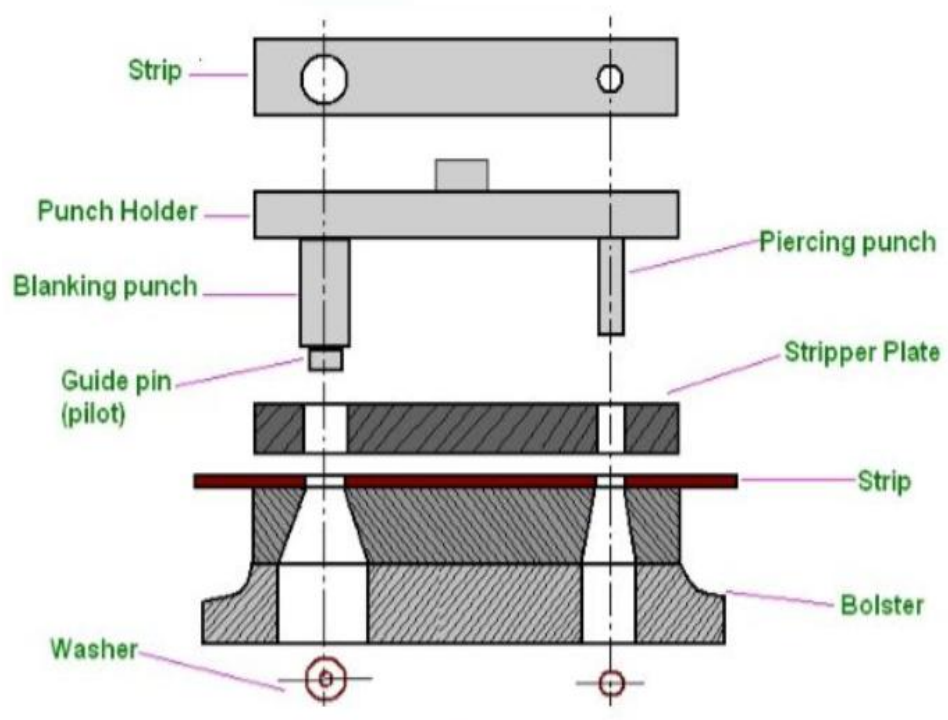

Fig 1: Elements of progressive die

\section{Literature Review}

A die is a sophisticated tool employing in hardware manufacturing industries for multiple functions such as cutting, shaping and forming mixture of products and apparatus. Strip layout planning is a key activity in design 
of progressive dies used in sheet metal industries. The sequence planning plays a vital role in progressive dies operations which initiates the rapid operation and minimizes the operating time. The Various researchers elsewhere in the world are attempted to develop CAD designs for progressive die. The research work carried on design of progressive die was addressed in this section, example Schaffer [8] and Nakahara et al. [9] were considered as pioneers, because first time they integrate the CAD/CAM techniques for the development of progressive dies. In same line other researchers were also implement the integration of the other techniques in CAD/CAM [10] environment.

Bergstrom et al. [11]studies on calculations of stripper size, punching forces and so on, these studies helps in enhance the improvements in design of dies. The parallel studies are performed in [12] on development of an automated nesting and its piloting system in the design of progressive dies. Another study addressed on development of information schemes used in the design of progressive stamping dies by using a forecast approach [13].The published work reported on application of progressive dies in stamping operation for making the parts with complex shapes [14-15]. In same line other works are published on implementation of CAD [16], incorporated modeling and process planning systems [17] for performing the blanking, piercing and bending operations in a single stroke. The new feature of separation of branch drawings from mail drawing in CAD/CAM system as final output presented in [18]. Sima et al. [19] presented a center carrier type of progressive die for Ubending pieces. Cheok et al. [20] reported the developments in cerebral development aided for progressive die design using PC support utensils. The design of strip type layouts using expert systems have been discussed is [21] which helps in layout assembles in all type of process and also supports to decide station requirements in piercing and operations. The intellectual CAPP design developments are presented in [22]. The existing CAD/CAM design systems in market are supporting greatly in multiple analysis such as design drafting and performance.

\section{Designing Of Progressive Die}

\subsection{Design of Strip Type Outline}

The Strip type out line management of the arithmetical al features of the element, tolerances, direction of sharp edges on stash bits etc. The strip outline design helps majorly in initial design verifications in preparation analysis of sheet metal pieces. All design dimensions and allocation of inside and outside aspects such as holes, absolute holes, inside outlines, outside outlines, incise, marks, boss, cups, niches and curves experienced by following standards of operational rules. It is observed that from the extensive literature survey, there is a lacuna in appropriate solution for strip outline designs, but acceptable design procedure using fundamental guidelines are prepares [23].

\subsection{Selection of DIE Components}

The major die elements such as gages, blocks, family of supporting plates of back, stripper, punch, pilots, dieset and fasteners performs key function in progressive die set. Particularly the dimension of the die block decides using width, breadth, length and sharp curves of sheet metals. The die gages are also depends on the thickness of the sheets, the two operations of design of die blocks and gages consumes less time. The dimension of stripper plate is pertinent to the dimension of die block. For positioning and punching, punching plates with sufficient thickness are uses widely. The design thickness of punch plate selected in proportional to functional punch height and pays attention that the thickness of punch plate meets the design dimension length, width of die block. Usually, the design dimension 10-12 mm thickness is selected for backup plate. The proper design of die-set involves appropriate selection of division quantity, dimensional tolerance limits of the component, punch clearance with die, and guideposts clearance with bushings.

\subsection{DIE Component Materials}

Tool steels are the ideal material mainly used for fabricate the die components used in different press working operations. Tool steels are widely using to create the die components focused to carry. In addition to this, steel design supports to build up high rigidity levels and scratch resistance during heat-treated. Another material AISI D2 is steel alloyed with chromium, molybdenum and vanadium which enhances different the properties like superior wear resistance, compressive strength, tempering and greater stability in hardening.

\subsection{Assembly and Modeling of DIE Components}

The proposed design model of progressive die consist two major pats, one is its plate elements and the other is die-set. The design model of plate elements necessitates the design dimension data of various elements like die block, gages and different stripper, punch, back plate thickness. The proposed work used PRO-E design software 
for modeling the die components with suitable sketch features contains line, plane, circle and fillet etc. The assembled die set of a progressive die shown in figure 2 .

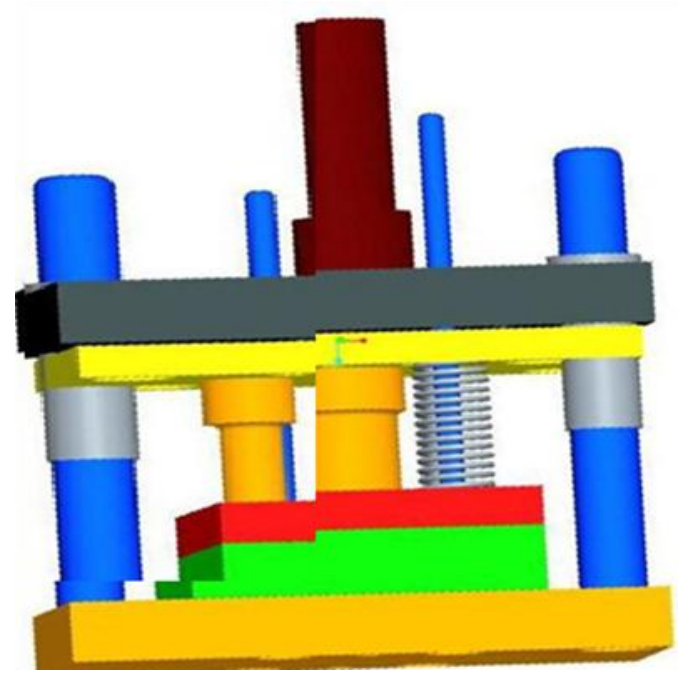

Figure 2: Modeled view of assembled progressive die

\section{CNC Part Programming}

The development of strip outline design is the initial activity of the proposed die design and which is a complex in design, time-consuming activity. The extent of complexity of proposed design enhances with the enhancement of number of die stations. Also, the strip out line design involves many stages of simulation, optimization including design process. In view of this, the computer programming based simulation study supports to obtain optimal design in less time consumption.

\subsection{Part Program for Top Plate}

The top plate of the progressive die consists of 8 holes with different diameters, drilled on the plate whose plate size is $100 \times 75 \times 20 \mathrm{~mm}$. In that six holes are drilled with a diameter of $8 \mathrm{~mm}$, other two drills have a diameters of $10 \mathrm{~mm}$ and $25 \mathrm{~mm}$. The prepared NC part program of the top plate was reported in this section.

$\%$

$: 001$

N001 G92 X0 Y0 Z2.0

N002 G90

N003 G00 X10.0 Y10.0 T01 S800 M03

N004 G01 Z-25 F100

N005 G00 Z2.0

N006 G00 X50 Y 10

N007 G01 Z-25 F100

N008 G00 Z2.0

N009 G00 X90.0 Y 10.0

N010 G01 Z-25 F100

N011 G00 Z2.0

N012 G00 X10.0 Y65.0

N013 G01 Z-25

N014 G00 Z2.0

N015 G00 X50.0 Y65.0

N016 G01 Z-25 F100 
N017 G00 Z2.0

N018 G00 X90 Y65.0

N019 G01 Z-25.0 F100

N020 G00 Z2.0

N021 G00 X33Y37.5T02 S800

N022 G01 Z-25.5 F100

N023 G00 Z2.0

N024 G00 X67 Y37.5 T03 S800

N025 G01 Z-25 F100

N026 G00 Z 2.0

N027 G28X0Y0Z0

N028 M05

N029 M30

The above part program was used to successfully make the holes on the top plate of the die set, the given Fig 3 (a-b) depicted that Fig 3 (a) explains about detailed drawing of the top plate and fig 3 (b) showed the modeled top plate of the progressive die were shown in below.

(a)

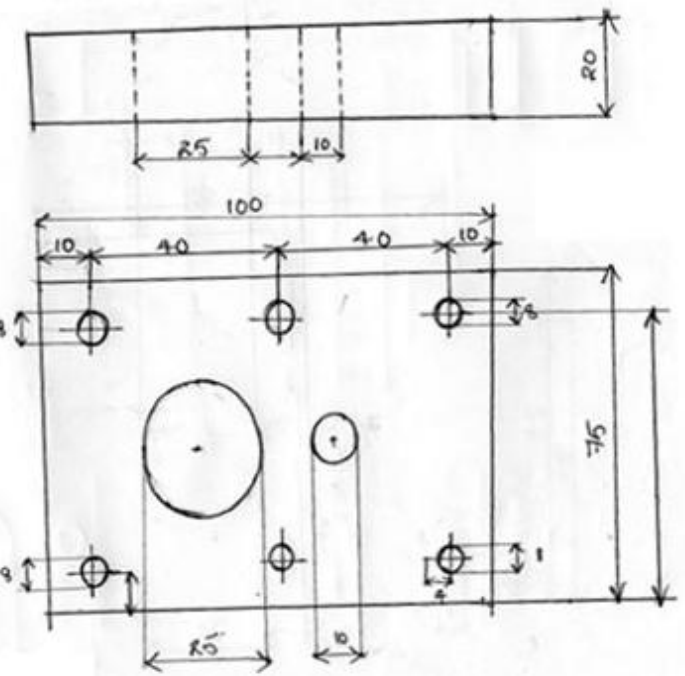

(b)

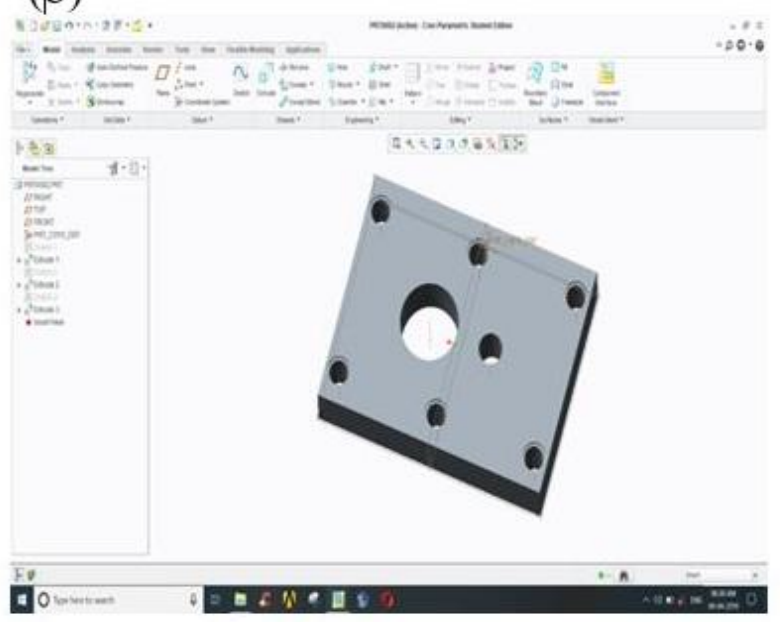

Figure 3:(a) Drawing details (b) 3-D model of the top plate

\subsection{Part Program For Bottom Plate}

The bottom plate of the progressive die consists of 8 holes same as top plate, the part program used for drill the holes on $15 \mathrm{~mm}$ thick plate was same as top plate. The top plate dimensions were taken as $115 \times 75 \times 15 \mathrm{~mm}$. In that six holes are drilled with a diameter of $8 \mathrm{~mm}$, other two drills have diameters of $10 \mathrm{~mm}$ and $25 \mathrm{~mm}$. The prepared $\mathrm{NC}$ part program of the top plate was reported in this section.

$\%$

: 001

N001 G92 X0 Y0 Z2.0

N002 G90

N003 G00 X10.0 Y10.0 T01 S800 M03

N004 G01 Z-20 F100 
N005 G00 Z2.0

N006 G00 X50 Y 10

N007 G01 Z-20 F100

N008 G00 Z2.0

N009 G00 X90.0 Y10.0

N010 G01 Z-20 F100

N011 G00 Z2.0

N012 G00 X10.0 Y65.0

N013 G01 Z-20

N014 G00 Z2.0

N015 G00 X50.0 Y65.0

N016 G01 Z-20 F100N017 G00 Z2.0

N018 G00 X90 Y65.0

N019 G01 Z-20 F100

N020 G00 Z2.0

N021 G00 X33Y37.5 T02 S800

N022 G01 Z-20 F100

N023 G00 Z2.0

N024 G00 X67 Y37.5 T03 S800

N025 G01 Z-20 F100

N026 G00 Z 2.0

N027 G28X0Y0Z0

N028 M05

N029 M30

The above part program was used to successfully make the holes on the bottom plate of the die set, the given Fig 4 (a-b) depicted that Fig 4 (a) explains about detailed drawing of the top plate and fig 4 (b) showed the modeled top plate of the progressive die were shown in below.

(a)
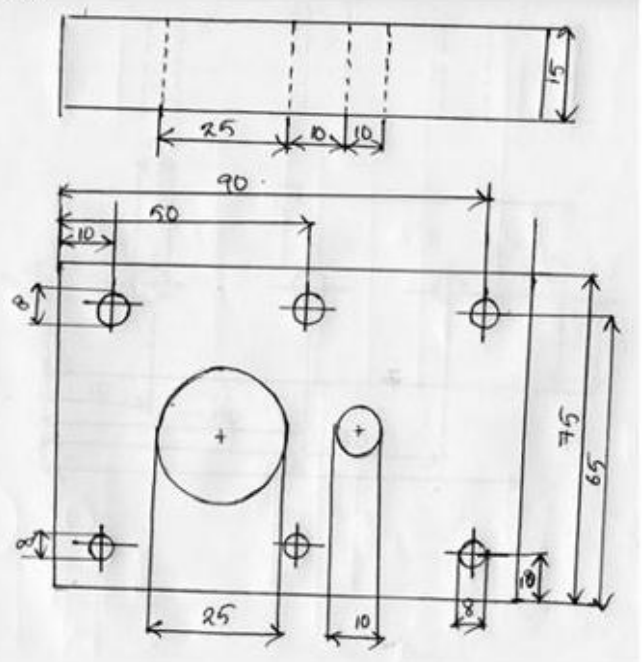

(b)

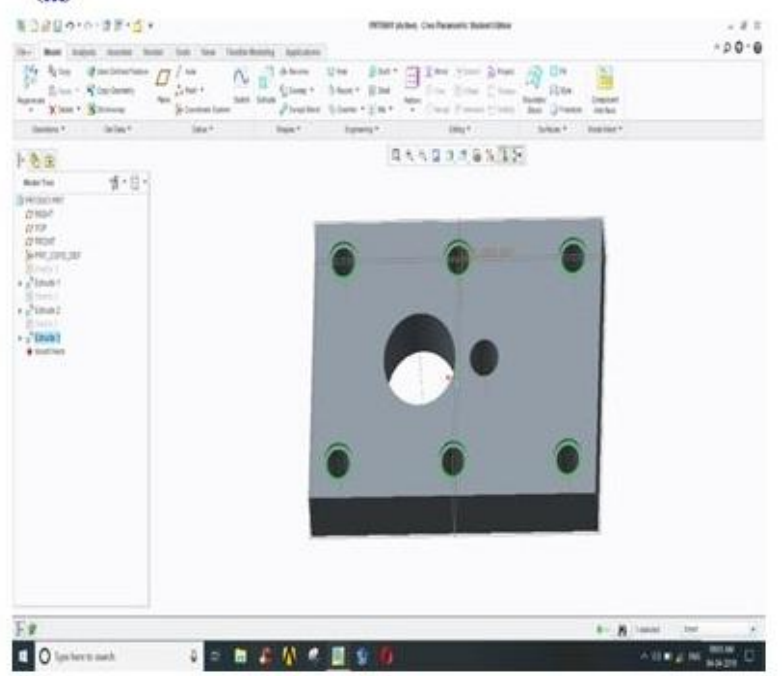


Figure4:(a) detailed drawing of bottom plate (b) 3-D Modelling of Bottom plate

\subsection{CNC part program of stripper}

The stripper of the progressive die consists of 3 holes with same diameter of $8 \mathrm{~mm}$ in the dimensions of $100 \times 25 \times 8 \mathrm{~mm}$. The prepared NC part program of the stripper was reported in this section.

$\%$

: 001

N001 G92 X0 Y0 Z2.0

N002 G90

N003 G00 X10.0 Y15.0 T01 S800 M03

N004 G01 Z-25 F100

N005 G00 Z2.0

N006 G00 X50 Y15

N007 G01 Z-25 F100

N008 G00 Z2.0

N009 G00 X90.0 Y15

N010 G01 Z-25 F100

N011 G00 Z2.0

N012 G28X0Y0Z0

N013 M05

N014 M30

The above part program was used to successfully make the holes on the stripper. The given Fig 5 (a-b) depicted that Fig 5 (a) explains about detailed drawing of the stripper plate and fig 5 (b) showed the view of the stripper.

(a)

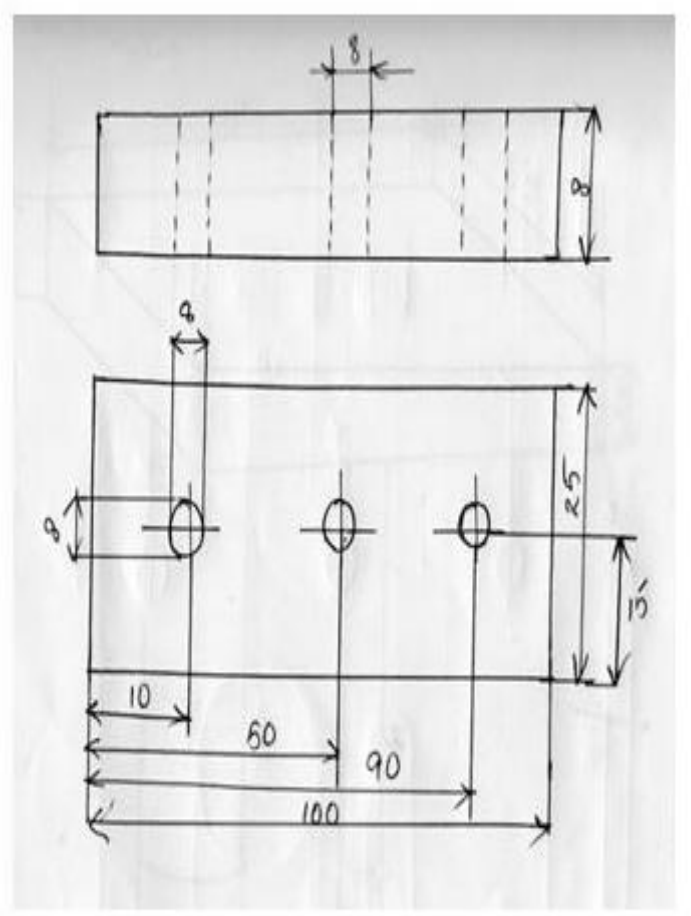

(b)

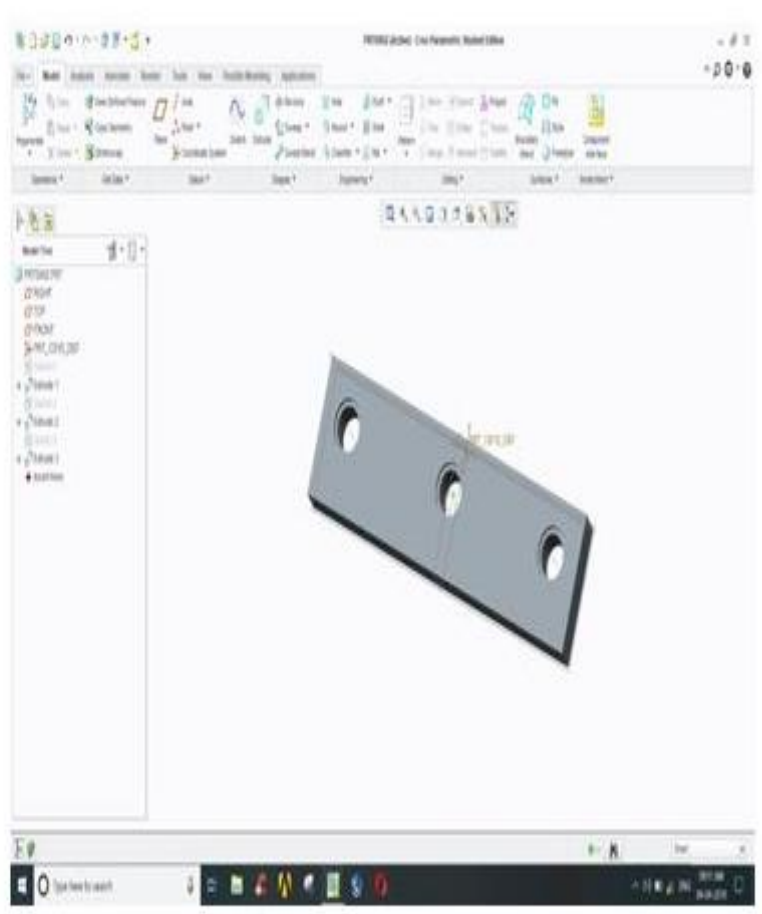


Figure 5: (a) Detailed drawing of stripper (b) 3-D Modelling of Stripper

\subsection{Part Program for Punch Holder}

The punch holder was machined on wire EDM to get accurate dimensions of the extended two cylindrical rods were shown in fig 6 . The dimensions of punch holder was taken as $115 \times 75 \times 15 \mathrm{~mm}$. Two cylindrical bars of length $50 \mathrm{~mm}$ and diameters of $25 \mathrm{~mm}$ and $10 \mathrm{~mm}$ were shown in fig 6 . In this process the material between two cylindrical bars was removed and those two bars were machined to get final dimensions as per the drawing was shown in fig 6.

$\%$

: 001 .

N001 G92 X0 Y0 Z2.0

N002 G90

N003 G00 X10.0 Y15.0 T01 S800 M03

N004 G01 Z-25 F100

N005 G00 Z2.0

N006 G00 X50 Y15

N007 G01 Z-25 F100

N008 G00 Z2.0

N009 G00 X90.0 Y15

N010 G01 Z-25 F100

N011 G00 Z2.0

N012 G28X0Y0Z0

N013 M05

N014 M30

Slot milling

N001 G00 G90X00 Y00 Z1 S800 M03

N002 Z-5

N003 G01 X20 F100

N004 G00 Z1

N005 X70 Y27.5

N006 X00 Y00 M30

In this program each step is allowed to cut $5 \mathrm{~mm}$ thickness, it needs 4 iterations to cut the $20 \mathrm{~mm}$ thick plate. The given figure $6(\mathrm{a}-\mathrm{b})$ shows the drawing details of the punch holder and repeat the program from X20 to X70. 
(a)

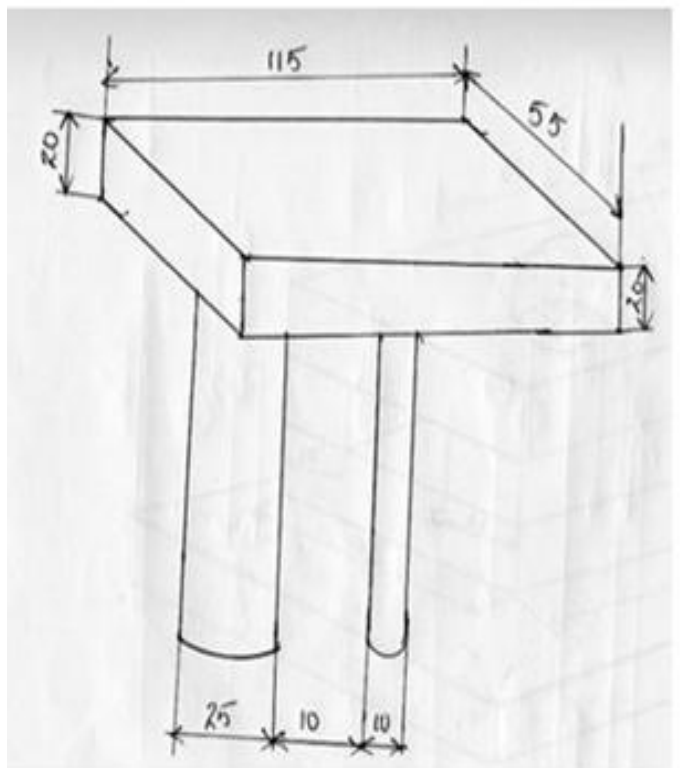

(b)

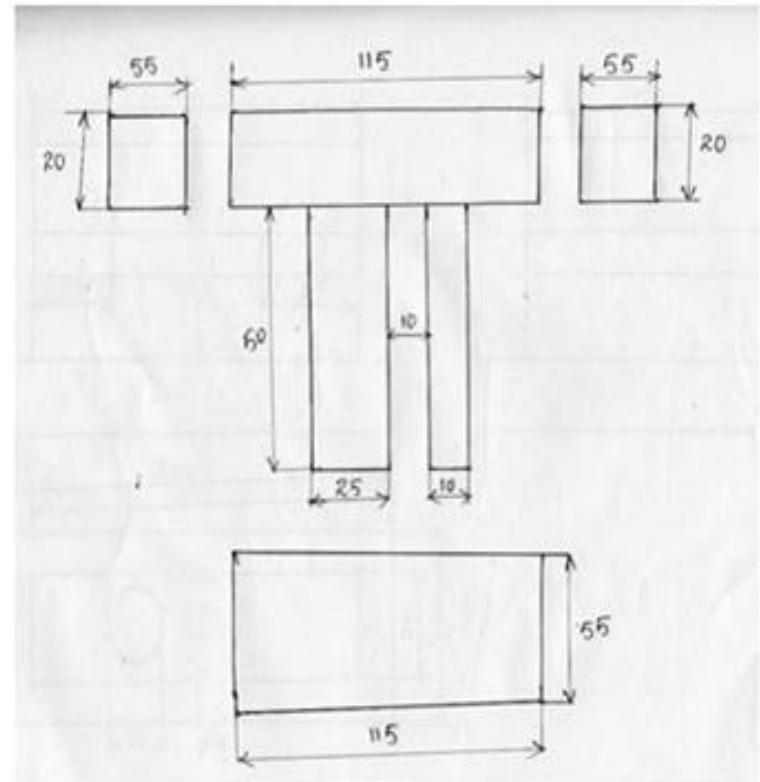

Figure 6: (a) and (b) Detailed drawing of the punch holder

The view of the punch holder, modeled in PRO-E software was shown below, where fig 6 (c) indicate the model of punch holder and fig 6 (d) represents the image of punched part.

(c)

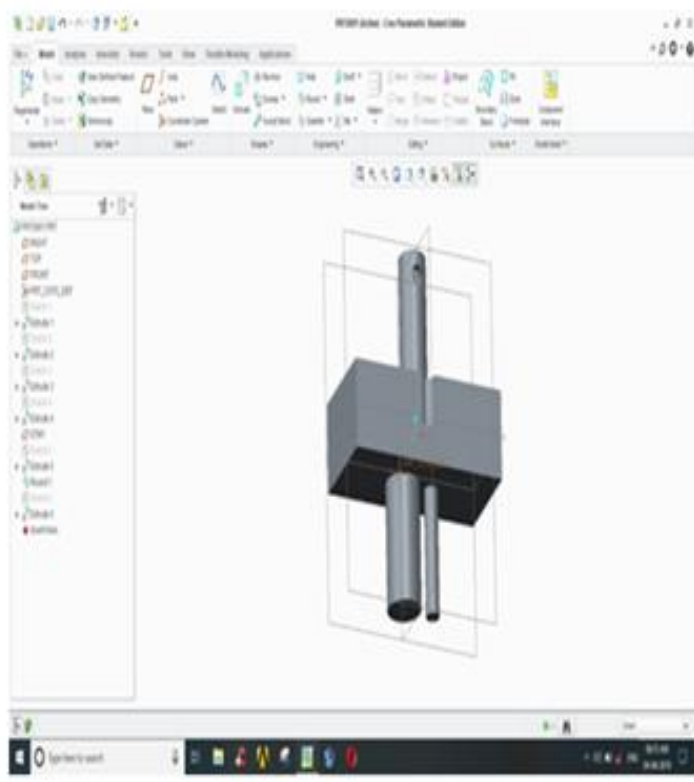

(d)

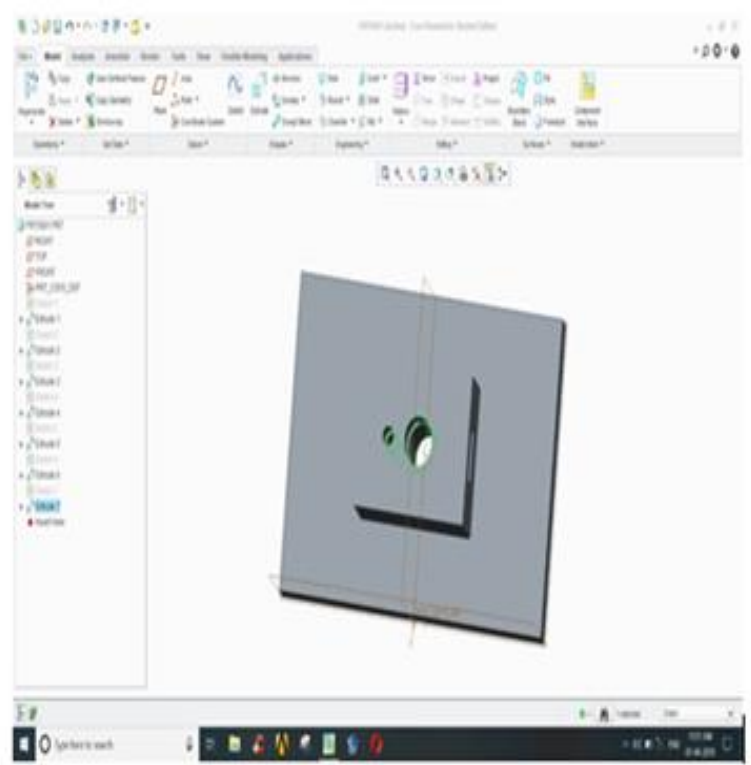

Figure 6: (c) 3-D model of the punch holder (d) 3-D Modelling of punched parts

In final stage, all machined die components are assembled and complete progressive die set up was shown in fig 7. 


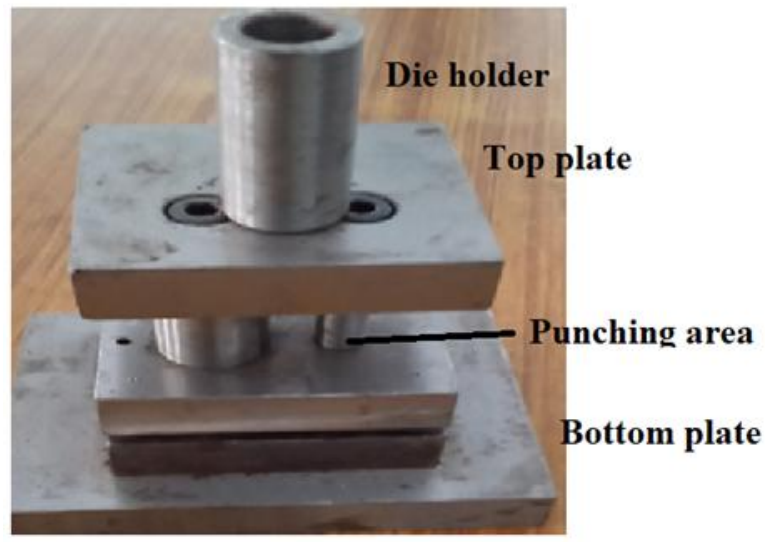

Figure 7:Assembly of machined elements

\section{Conclusion}

This paper presented the design and analysis of progressive die using PRO-E software tool and from the design analysis of proposed die, following inferences are drawn:

1. All the die set parts were clearly designed and 3-D modeling software such as PRO-E was used to model them.

2. Separate CNC part programs were prepared to machine the die set elements such as top plate, bottom plate, stripper and punch holder.

3. All the prepared part programs were tested and successfully executed on FANUC Controlled CNC milling machine.

\section{Acknowledgement}

The authors would like to thank the Principal and Management of Lakireddy Bali Reddy College of Engineering for permitting to publish this paper.

\section{References}

Ostergaard, D. E., National Tool, D., and Committee, P.M.A.T.M., (1963) “Basic Die Making,” McGraw-Hill, 2nd Ed.

Donaldson, C., Cain, G. H. L., and Goold, V. C., (1976) “Tool Design,” Tata McGraw-Hill, 3rd Ed., pp. 632780.

Paquin, J.R. \& Crowley, R.E (1987) Die design fundamentals, Industrial Press Inc. Second edition, NY, 244

Nakagawa T, Futamura S and Murata T, (1993) Small-lot-stamping production by progressive unit dies CIRP Annals 42, 313-317

Suchy, I. (1998). Handbook of Die Designing (Second Edi).

Ivana Shcy, (2006) Handbook of Die Design, 2nd edition McGrawth-Hill

Joshi, P. F. (2010) "Press Tools: Design and Construction," S. Chand Publishing, 2nd Ed., pp. A1 -

B98, G1, H12, M1-M29.

Schaffer, G., (1971) Computing design of progressive die. American Machinist, 115 (2), $73-75$.

Nakahara, S., et al., (1978) Computer aided progressive die design. In: Proceedings of the 19th machine tool design research conference, 13-15 September, Manchester, UK. London: MacMillan, 171-176

Shirai, K., Murkami, H. (1989). A compact and practical CAD/CAM system for progressive dies. Bulletin of the Japan Society of Precision Engineering, 23, 25-30.

Bergstrom, K., et al., (1988) Computer aided design of progressive die. In: J.L. Chersot and E. Ohate, eds. Modeling of Metal Forming Processes. New York: Kluwer, 155-162.

Ghatrehnaby, M., Arezoo, B. (2009) A fully automated nesting and piloting system or progressive dies. Journal of Materials Processing Technology, 20(9), 525-535

Duffy, M. R., and Sun, Q. (1991) Knowledge-based design of progressive stamping dies. Journal of Materials Processing Technology, 28, 221-227.

Rehaman I, Reddy S, Matta M and Murthi G,(2014) Design and analysis of progressive die for chain link plate International Journal of Science Engineering and Advance Technology2, 763-768

Choi J and Kim C (2001) A compact and practical CAD/CAM system for the blanking or piercing of irregular shaped-sheet metal products for progressive working Journal of Materials Processing Technology110, 36-46 
Li J Y, Nee A Y C, and Cheok B T (2002) Integrated feature based modelling and process planning of bending operations in progressive die design, International journal of advanced manufacturing technology, 20, 883895

Cheok, B. T., Foong, K. Y. and Nee, A. Y. C. (1996). An intelligent planning aid for the design of progressive dies. Proceeding of Institution of Mechanical Engineers - Part B: Journal of Engineering Manufacture, 210, 25-35.

Shirai, K., Murkami, H. (1989). A compact and practical CAD/CAM system for progressive dies. Bulletin of the Japan Society of Precision Engineering, 23, 25-30.

Sima, S.-B., Lee, S.-T. and Jang, C.-H. (2004). A study on the development of center carrier type progressive die for U-bending part process. Processing Journal of Materials Technology, 1005-1010.

Cheok, B. T., Foong, K. Y. and Nee, A. Y. C. (1996). An intelligent planning aid for the design of progressive dies. Proceeding of Institution of Mechanical Engineers - Part B: Journal of Engineering Manufacture, 210, $25-35$.

Ismail, H. S., Chen, S. T. and Hon, K. K. B. (1996). Automated design of progressive dies. Proceeding of Institution of Mechanical Engineers Part B: Journal of Engineering Manufacture, 210, 367-376.

Zheng, J., Wang, Y. and Li, Z. (2007). KBE-based stamping process paths generated for automobile panels. International Journal of Advanced Manufacturing Technology, 31, 663-672.

S. Kumar, R. Singh (2011) An automated design system for progressive die, Expert Systems with Applications $38,4482-4489$ 